\title{
Mgr Laflèche et la Confédération
}

\section{Jacques Lacourcière}

Volume 34, 1967

URI : https://id.erudit.org/iderudit/1007422ar

DOI : https://doi.org/10.7202/1007422ar

Aller au sommaire du numéro

Éditeur(s)

Les Éditions Historia Ecclesiæ Catholicæ Canadensis Inc.

ISSN

0318-6172 (imprimé)

1927-7067 (numérique)

Découvrir la revue

Citer cet article

Lacourcière, J. (1967). Mgr Laflèche et la Confédération. Sessions d'étude -

Société canadienne d'histoire de l'Église catholique, 34, 63-66.

https://doi.org/10.7202/1007422ar

Tous droits réservés @ Les Éditions Historia Ecclesiæ Catholicæ Canadensis Inc., 1968
Ce document est protégé par la loi sur le droit d'auteur. L'utilisation des services d'Érudit (y compris la reproduction) est assujettie à sa politique d'utilisation que vous pouvez consulter en ligne.

https://apropos.erudit.org/fr/usagers/politique-dutilisation/ 


\section{Mgr Laflèche et la Confédération}

Mars 1865 : les députés canadiens étudient le projet de confédération tel que soumis à la Chambre. Les « rouges», s'ils ne se prononcent pas ouvertement contre le projet, y apportent tellement de restrictions que leur attitude est' surtout négative. Les « bleus ", à deux exceptions près, sont en faveur de l'union des colonies. A la séance de mardi, le 7 mars, Cartier affirme que le clergé appuie la confédération de son influence. Trois jours plus tard, soit le 10, le député des TroisRivières, Charles Boucher de Niverville, n'hésite pas à affirmer publiquement que le haut clergé de son diocèse est' en faveur du projet :

Je me suis adressé à deux membres du clergé du district des Trois-Rivières, hommes d'une grande érudition et éminemment qualifiés à me donner une opinion sur le projet de confédération; hommes parfaitement dégagés de tout esprit de parti, n'ayant aucun intérêt politique ou aucune ambition personnelle à faire passer avant les intérêts du pays, et dont l'opinion était garantie par une vie d'études et de travail constamment employée au bonheur et à la prospérité de leurs compatriotes et du pays, et à la protection de nos institutions religieuses [...]. Tous deux se sont accordés à répondre qu'ils étaient en faveur de la confédération projetée des provinces britanniques anglaises de ce continent 1 .

Voilà bien caractérisés et Mgr Louis-F. Laflèche et son attitude vis-à-vis la Confédération.

A cette époque, Mgr Laflèche n'était pas, il est vrai, évêque des Trois-Rivières. Il occupait le poste de grand vicaire et d'administrateur du diocèse. L'évêque était alors Mgr Thomas Cooke.

Dans sa lettre du 2 mars 1865, au député des Trois-Rivières, le futur évêque énumère les raisons qui doivent nous inciter à accepter le projet. Ces raisons, nous les retrouvons en partie dans le mandement de juin 1867.

Mgr Laflèche avoue à de Niverville, qu'il appelle a mon cher Charles», qu'il n'a pas fait d'étude spéciale du projet de confédération. Mais la situation politique est telle qu'il faut $y$ apporter une solution immédiate. Le rappel de l'Union étant chose impossible, seule la confédération nous "offre réellement une planche de salut", car l'union législative amènerait la prépondérance du Haut-Canada, notre déchéance et "l'anéantissement de nos institutions ". Une autre raison en faveur du projet : il a été rédigé par des " hommes de la spécialité ».

On ne peut mettre en doute aujourd'hui l'expérience, la capacité et le patriotisme des hommes qui ont élaboré ce projet. Les explications qu'ils ont données, et les raisons et motifs sur lesquels ils se sont appuyés, bien qu'attaqués violemment, n'ont pu être ébranlés, ni réfutés

1 Débats parlementaires (1865), p. 947. 
par leurs adversaires, qui n'ont eu rien d'acceptable à présenter à la place ${ }^{2}$.

Lorsque l'on connaît l'attitude de Mgr Laflèche envers le parti rouge, on n'est pas surpris de cette condamnation globale de l'attitude de l'opposition. "Cette minorité a-t-elle reçu le privilège de l'infaillibilité ? N'a-t-elle donc pas assez d'intelligence pour comprendre que la division parmi nous est le plus grand malheur que nous ayons à craindre ${ }^{3}$ ?"

En mars 1865, le projet de confédération apparaissait donc à Mgr Laflèche comme "ce qu'il y a de mieux pour nous dans les circonstances actuelles ". Mais le vote final, pris en Chambre le 10 mars, révéla que la minorité opposante était plus forte qu'il ne l'avait prévu, puisque le projet ne fut approuvé que par une majorité de cinq voix pour le Bas-Canada. La veille de cette votation, l'abbé Taschereau, de Québec, avait soumis aux meilleurs canonistes de Rome une partie du texte des Résolutions de Québec, surtout le passage se rapportant à la question du divorce, à savoir quelle devait être l'attitude de la députation catholique sur ce sujet. Cette question du divorce a inquiété le grand vicaire des Trois-Rivières qui, à la fin de cette année 1865, demanda à l'abbé Taschereau de préciser la nature de son intervention à Rome.

Le 20 décembre [1865], l'abbé Taschereau écrit une nouvelle lettre à Mgr Laflèche l'informant qu'il n'a pas soumis aux canonistes romains le texte même du projet de la confédération, comme l'affirmait le Journal des Trois-Rivières. Laflèche avait-il été l'inspirateur de l'article signé "Un Catholique sincère ", on ne le sait. Dans la même lettre, l'abbé Taschereau laisse échapper la phrase suivante :

Voilà donc Mgr de Montréal revenu chez lui. Espérons qu'il va se tenir en paix et qu'il y laissera les autres ${ }^{4}$.

Le projet de Confédération devenu réalité juridique par la sanction royale du 29 mars 1867, il devenait important de savoir quelle serait l'attitude des évêques bas-canadiens vis-à-vis la nouvelle constitution et les élections qui suivraient. Le 8 mai 1867, le coadjuteur du diocèse des Trois-Rivières, qui avait droit de succession, écrit à l'évêque de Québec lui suggérant que l'épiscopat canadien publie un mandement sur la confédération. Laflèche croit que ce mandement devrait être rédigé dans un assez bref délai pour qu'il puisse être publié aussitôt la proclamation de la Constitution. C'est donc Mgr Laflèche qui est l'instigateur des mandements épiscopaux sur le sujet. Un passage du texte de Mgr Baillargeon en fait foi :

Mais il faudrait certainement que ceux [les évêques] du Bas-Canada s'entendissent tous, et s'accordassent à publier chacun leur mandement dans le même but sur le projet en question. Il faudrait donc y engager

2 Lettre de Monseigneur Laflèche à Boucher de Niverville, Pointe-du-Lac, 2 mars 1864 [sic] (A.S.T.R., B2-B31-A). Il y a ici erreur de datation, il faut lire 1865 .

3 Ibid.

4 A.S.T.R., A 1-T 99-04. 
l*Evêque de Montréal et Celui de St. Hyacinthe. Or personne ne saurait mieux faire la chose que Votre Grandeur, qui a le mérite d'avoir suggéré le dit mandement. Pour l'Evêque de Rimouski, vous pouvez le regarder comme prêt à se joindre à nous. Il est plein de zèle pour cette bonne cause : il sera donc prêt, ainsi que votre tout dévoué serviteur ${ }^{5}$...

Mgr Laflèche voulait que les évêques du Bas-Canada fassent taire l'opposition. Tout en travaillant à la rédaction de la lettre pastorale, le coadjuteur des Trois-Rivières essaie de convaincre les évêques de Montréal et de Saint-Hyacinthe de publier un mandement. Il croit avoir réussi et fait part du résultat de ses démarches à l'évêque de Québec qui, dans une lettre du 29 mai, le félicite de son succès ${ }^{6}$.

Le 8 juin 1867, sous la signature de Mgr Thomas Cooke, est publiée une lettre pastorale sur la Confédération. Même si Mgr Laflèche n'y a pas apposé sa signature, personne n'est dupe. L'âme inspiratrice est certainement l'auteur des \& Quelques considérations sur les rapports de la Société civile avec la Religion et la Famille ». La lettre pastorale reprend certaines idées, certaines comparaisons employées par Mgr Laflèche dans sa lettre à Niverville : comparaison entre la constitution d'un pays et celle d'un individu, nécessité de consulter un spécialiste, désarroi politique dans lequel se trouve le pays, échec de l'Union, notre mise en infériorité numérique. La Confédération, obstacle au désir ou à la menace d'annexion aux Etats-Unis, voilà une idée que le mandement développe assez longuement. Les quelques voyages que Mgr d'Anthédon avait effectués chez nos voisins l'avaient nettement convaincu que les Etats-Unis ne possédaient pas le mode de gouvernement idéal. Pour Mgr Laflèche, "la lutte véritable était entre la Confédération et l'annexion ».

La Confédération n'est pas non plus un acte de trahison, comme l'affirme le parti rouge. "Elle a été discutée assez longuement, examinée assez scrupuleusement par les hommes les plus dévoués et les plus éclairés de toutes les provinces, pour lever tout doute à cet égard." Il y a bien de l'inconnu, mais il faut s'en remettre à la divine Providence, "qui nous a toujours protégés d'une manière visible dans les épreuves que nous avons eu à traverser comme peuple ".

Face à la nouvelle constitution, les catholiques canadiens se doivent d'adopter l'attitude suivante : se conformer au nouvel état des choses, cesser l'opposition à la Confédération et, aux prochaines élections, élire les meilleurs hommes.

La lettre pastorale de l'évêque des Trois-Rivières souleva l'enthousiasme ou l'indignation. Les journaux commentèrent assez longuement la prise de position de l'évêque des Trois-Rivières. Georges-Etienne Cartier poussa même la reconnaissance jusqu'à écrire une assez longue lettre à Mgr Laflèche pour le remercier de sa prise de position. Dans

5 Lettre de Mgr Turgeon à Laflèche, 14 mai 1867, A.S.T.R., A 1-10-13.

6 A.S.T.R., A 1-10-15. 
cette lettre du 13 juin, Cartier se dit assuré que le mandement * contient les inspirations et les sentiments de Votre Grandeur ».

Ce mandement, dit-il, fera époque dans les Annales de l'Episcopat du Canada ?.

Le futur ministre de la milice relève dans le mandement l'insistance sur les embarras et les difficultés des deux Canadas et assure Mgr Laflèche que le nouveau gouvernement travaillera à faire disparaître ces problèmes.

Pour Mgr Laflèche, surtout après le $1^{\text {er }}$ juillet 1867 , on ne peut plus se permettre d'être contre la Confédération. Ceci l'amènera à prendre position ouvertement pour le parti conservateur, lors de la première campagne électorale fédérale. Plusieurs curés du diocèse des Trois-Rivières consultèrent Mgr Laflèche, à savoir quelle conduite tenir au sujet du vote. Le 20 août 1867, il donna comme réponse à la question :

Un électeur peut-il voter en conscience pour un candidat qui déclare qu'il appartient au parti libéral et qu'il est décidé à le supporter, sachant que ce parti qui a combattu la nouvelle constitution de toutes ses forces a décidé dans le mois de mai dernier qu'il fallait s'y opposer et la combattre, bien qu'il dise à présent qu'il l'accepte mais qu'il veut la modifier?

Réponse. Nous croyons qu'un électeur ne peut voter en conscience de cette manière, et qu'en votant ainsi il agit fort imprudemment et se rend coupable de péché, attendu que les évêques de la province, et notamment l'évêque des Trois-Rivières, ont décidé et fait connaître à leurs diocésains qu'on est obligé sous peine de péché d'accepter la nouvelle constitution et de voter pour des hommes qui sont franchement et sincèrement décidés à la faire bien fonctionner ${ }^{8}$.

Le 9 septembre 1867, dans une lettre au curé Boucher, de SaintAntoine-de-la-Rivière-du-Loup, aujourd'hui Louiseville, Mgr Laflèche se réjouit du succès conservateur et affirme que la "lutte qui partage en deux camps ennemis nos compatriotes, n'est que la grande lutte entre le bien et le mal », lutte qui existe depuis le début du monde. Les libéraux, identifiés ici aux partisans du mal, deviendront la hantise de Mgr Laflèche qui voit en eux des émules des garibaldiens. Pour lui, l'autorité devait être respectée et la Confédération était devenue décision de l'autorité.

Jacques LAcourcière Trois-Rivières

7 A.S.T.R., B 2-47-04.

8 Robert Rumilly, Mgr Laflèche et son temps. 